\title{
Proteomic analysis of pancreas in miniature pigs according to developmental stages using two-dimensional electrophoresis and matrix-assisted laser desorption/ionization-time of flight mass spectrometry
}

\author{
Sun Shin $\mathrm{Yi}^{1}$, Il Yong $\mathrm{Kim}^{2}$, Sae Jin $\mathrm{Oh}^{3}$, Hye Jung Yeom ${ }^{4}$, Su Cheong Yeom ${ }^{5}$, \\ Seung Yong Hwang ${ }^{6}$, Je Kyung Seong ${ }^{2 *}$ \\ ${ }^{1}$ Department of Biomedical Laboratory Science, College of Biomedical Sciences, Soonchunhyang University, Asan, Korea \\ ${ }^{2}$ Laboratory of Developmental Biology and Genetics, College of Veterinary Medicine, \\ BK21 Plus Program for Creative Science Research, BIO-MAX institute, Seoul National University, Seoul, Korea \\ ${ }^{3}$ Department of Pathology and Laboratory of Immune Regulation, College of Medicine, Seoul National University, Seoul, Korea \\ ${ }^{4}$ Transitional Research Institute, College of Medicine, Seoul National University, Seoul, Korea \\ ${ }^{5}$ Biomedical Center for Animal Resource and Development, BIO-MAX Institute, Seoul National University, Seoul, Korea \\ ${ }^{6}$ Department of Biochemistry, Hanyang University, Ansan, Korea
}

\begin{abstract}
Organ transplantation is limited by the shortage of human organs. Many studies have sought to overcome this hurdle by using animal organs. Porcine organs, especially from miniature pigs, have been used for organ xenotransplantation rather than nonhuman primates. While the molecular profiling for transplantation is well known in humans and rodents, the situation for pigs is almost completely unknown. The present study examined protein regulation of the developing stages of the pancreatic proteome (4 day-old miniature neonate, 19 day-old miniature piglet, and 14 month-old miniature adult pigs) using twodimensional gel electrophoresis and matrix assisted laser desorption/ionization-time of flight mass spectrometry. Thirteen different expressed spots were observed and nine were identified. The data presented within this study provides critical direction relating to the development of pancreas of miniature pigs, which will assist future proteome analysis of the pancreas, and advance our understanding of the hurdles facing xenotransplantation.
\end{abstract}

Key words: Human organ, pancreas, miniature pig, proteome, 2-DE MALDI-TOF

Received 21 September 2013; Revised version received 11 January 2014; Accepted 21 January 2014

The increasing shortage of human donor organs has provoked interest in the possible use of animal organs for transplantation into humans [1-3]. Organ transplants from nonhuman primates have been studied as replacements for human organs. However, using organs of nonhuman primates can be dangerous, and their organs can be too small for transplanatation into adult humans [1]. Pigs are the most likely candidate for xenotransplantation [4,5]. Moreover, as a potential xenotransplantation source, pigs have to be managed under conditions of stringent bioexclusion. Miniature pigs produced by a selective breeding system are recommended [6,7].

Miniature pigs have many physiological similarities with humans and provide some breeding and manipulation advantages compared to non-human primates [8]. The organs commonly used from miniature pigs are the heart, kidney, liver and pancreas. The pancreas controls endocrine, exocrine and glucose metabolism through the creation of insulin. Porcine pancreatic tissue can be a

*Corresponding author: Je-Kyung Seong, Laboratory of Developmental Biology and Genetics, College of VeterinaryMedicine,BK21 Program for Veterinary Science, BIO-MAX institute, Seoul National University, Seoul 151-742, Korea

Tel: +82-2-883-8395; Fax: +82-2-875-8395; E-mail: snumouse@snu.ac.kr

This is an Open Access article distributed under the terms of the Creative Commons Attribution Non-Commercial License (http://creativecommons.org/licenses/ by-nc/3.0) which permits unrestricted non-commercial use, distribution, and reproduction in any medium, provided the original work is properly cited. 
good resource of transplantation therapy for human diabetic patients [9-11]. Transplantation of porcine pancreatic islets into non-human primates or other species has been documented [12-14]. However, the characteristics of pancreatic protein expression in pigs are ill-understood, while the expression of pancreatic proteins in humans and rodents is better defined.

Presently, pancreatic protein expression was examined chronologically using a miniature neonate pig (4-dayold), miniature piglet (19-day-old) and miniature adult pig (14-months-old). Proteins that were differentially expressed during development were revealed by twodimensional electrophoresis (2-DE) and matrix assisted laser desorption/ionization-time of flight mass spectrometry (MALDI-TOF MS). While the repository of identified porcine proteins in Swiss-Prot and NCBI databases are relatively scant, these sources were used presently to help identify the differentially expressed proteins. The data should aid future proteome analyses.

\section{Materials and Methods}

\section{Laboratory animals}

The miniature pigs were housed in the air barrier facility of the Center for Animal Resource Development at Seoul National University. Three pigs (male 4-old-, 19-day- and 14-month-old miniature pig) having different ages and developmental stages were used. They were conditioned in the same room at $24 \pm 2^{\circ} \mathrm{C}$ with a 12/12 (light/dark) cycle. Air and water were filtered, and all equipment and food were sterilized before use. This study was approved as an animal use protocol by the Institutional Animal Care and Use Committee at SNU (SNU-IACUC approval number: SNU-060613-5). Intramuscular anesthesia was achieved using a mixture of $2 \mathrm{~mL}$ ketamine $\cdot \mathrm{HCl}(50 \mathrm{mg} / \mathrm{mL} / \mathrm{kg}), 1 \mathrm{~mL}$ xylazin $(2.3 \mathrm{mg} / \mathrm{mL} / \mathrm{kg})$ and $1 \mathrm{~mL}$ atropine sulfate $(0.5 \mathrm{mg} / \mathrm{mL} /$ $10 \mathrm{~kg}$ ) during every painful/stressful procedure. The abdomen of each pig was shaved and disinfected with polyvinylpyrrolidone-iodine. The animals were immobilized on a surgical plane-table by adhesive ties. A median laparotomy was performed. The pancreas from the animals were nipped off aseptically and stored in liquid nitrogen while being transported to the laboratory.

\section{Sample preparation for 2DE}

The pancreas of each pig (one miniature pig for each age stage, respectively)was removed immediately after sacrifice and stored at $-70^{\circ} \mathrm{C}$ until used. In briefly, the peritoneal of the miniature pigs under the anesthesia were pre-chilled by filling of large quantity of ice before removing the pancreas. The pancreas was collected from the distal end of normal pancreas immediately from the animals and snap-frozen in liquid nitrogen, and stored at stored at $-70^{\circ} \mathrm{C}$. The frozen pancreas tissues $(1 \mathrm{~g})$ in a mortar were grounded to powder under the constant addition of liquid nitrogen. The powder is normally suspended in $900 \mu \mathrm{L}$ lysis buffer (7 M urea, $2 \mathrm{M}$ thiourea, $2 \%$ w/v CHAPS, 2\% pharmalyte $\mathrm{pH} 3-10,100$ $\mathrm{mM}$ DTE). Samples were centrifuged at 50,000 rpm at $4^{\circ} \mathrm{C}$ for $1 \mathrm{~h}$. The supernatant was carefully removed and immediately frozen at $-70^{\circ} \mathrm{C}$.

\section{DE}

2D-polyacrylamide gel electrophoresis (PAGE) was performed as previously described [15]. Aliquots containing $1 \mathrm{mg}$ total protein were diluted in lysis buffer to a total volume of $450 \mu \mathrm{L}$. The samples were applied to a $240 \mathrm{~mm}$, immobilized, nonlinear $\mathrm{pH}$ 3-10 IPG Drystrip (Amersham Pharmacia Biotech, Piscataway, NJ, USA), which was rehydrated for at least $12 \mathrm{~h}$. After rehydration, the strips were focused at $30 \mathrm{~V}$ for $3 \mathrm{~h}$, $100 \mathrm{~V}$ for $1 \mathrm{~h}, 200 \mathrm{~V}$ for $1 \mathrm{~h}, 500 \mathrm{~V}$ for $1 \mathrm{~h}, 1,000 \mathrm{~V}$ for $1 \mathrm{~h}$ and finally at $8,000 \mathrm{~V}$ for $11 \mathrm{~h}$ to obtain approximately 90,000 Vh $\left(\right.$ Ettan $^{\mathrm{TM}}$ IPGphor $^{\mathrm{TM}}$ II IEF systems; Amersham Pharmacia Biotech). Once isoelectric focusing was completed, the strips were equilibrated in $6 \mathrm{M}$ urea containing $20 \% \mathrm{v} / \mathrm{v}$ glycerol, $2 \% \mathrm{w} / \mathrm{v}$ sodium dodecyl sulfate (SDS) and $0.01 \% \mathrm{w} / \mathrm{v}$ BPB with $10 \mathrm{mM}$ tributyl phosphine (Flukachemie, Buchs, Switzerland). SDS-PAGE was performed using an $8-18 \%$ separating gel without a stacking gel using the Ettan Dalt system (Amersham Pharmacia Biotech) twice per each agedgroup for the confirmation of separated gel-spot trends. The second dimension electrophoresis was carried out overnight at $3 \mathrm{~W} / \mathrm{gel}$ at $20^{\circ} \mathrm{C}$. The gels were stained with Coomassie G-250 (Bio-Rad Laboratories, Hercules, CA, USA).

\section{Protein visualization and image analysis}

The gels were stained with Coomassie G-250 (Bio$\mathrm{Rad})$ as previously described [12]. The stained gels were scanned using a GS 800 photometer (Bio-Rad) and analyzed with the ImageMaster ${ }^{\mathrm{TM}}$ 2D Platinum Software version 5.0 (GeneBio, Geneva, Switzerland). The digitalized 2DE gel images were compared by a matching method 
(Image master 5.0; Amersham Biosciences). Differentially expressed spots ( $>3$-fold and $<1 / 3$-fold) were analyzed and annotated.

\section{In-gel digestion}

The spots were cut into smaller pieces and digested using $12.5 \mathrm{ng} / \mu \mathrm{L}$ trypsin (Promega, Madison, WI, USA) in $50 \mathrm{mM}$ ammonium bicarbonate, $\mathrm{pH} 8.0$, as previously described [16]. For MALDI-TOF MS analysis, the tryptic peptides were concentrated on a POROS 50 R2 column (Applied BioSystems, Foster City, CA, USA). After subsequent washing steps of column with $70 \%$ acetonitrile (can) in 5\% FA, 100\% can and 5\% FA, the samples were loaded into a POROS $50 \mathrm{R} 2$ column and washed with $5 \%$ FA. The sample was eluted with $2 \mu \mathrm{L}$ of matrix solution consisting of $10 \mathrm{mg} / \mathrm{mL} \alpha$-cyano-4-hydroxycinnamic acid (Sigma-Aldrich, St. Louis, MO, USA) and then dropped onto a MALDI sample plate [24].

\section{Protein identification by MALDI-TOF}

MALDI-TOF MS was performed using a Voyager DE-PRO spectrometer (Applied Biosystems) equipped with a $337 \mathrm{~nm}$ nitrogen laser. The instrument was operated at an accelerating voltage of $20 \mathrm{kV}$, positive ion reflection mode, voltage grid $74.5 \%$, guide wire voltage $0 \%$ and delay-time of $120 \mathrm{~ns}$. The spectra were internally calibrated using the trypsin autolysis products $(842.51[\mathrm{M}+\mathrm{H}]$ and $2211.11[\mathrm{M}+\mathrm{H}])$, and searching in Swiss-Prot identified the proteins and NCBI database using Mascot (Matrix Science, London, UK). Monoisotopic peaks $[\mathrm{MH}+]$ were selected and all the searches were analyzed with a $50 \mathrm{ppm}$ mass tolerance.

\section{Results}

\section{Protein identification by MS}

Porcine pancreatic proteins that were differentially expressed were identified and compared according to the developmental stage. Pancreatic proteins were extracted and analyzed by $2 \mathrm{DE}$. After the resolved proteins were visualized by Coomassie blue staining, 2-DE was repeated in three independent experiments for the three pairs of matched samples (Figure 1). For each sample, the three gels with the best resolution were selected for analysis. Spot intensities were analyzed using Image Master $^{\mathrm{TM}}$ software (Geneva Bioinformatics, S.A, Geneva, Switzerland). Among the 289 protein spots detected, 13 differentially expressed spots were identified. The protein spots up-regulated more than 3-fold or down-regulated less than 1/3-fold down-regulation were selected, excised from the gels and digested. Peptide fingerprinting was accomplished by MALDI-TOF MS. Peptide mass data were identified by Mascot. Thirteen differentially expressed protein spots were evident. Of these, nine were identified (Table 1) and their functions established based on a search at http://www.ebi.ac.uk/ego (Table 1).

\section{Classification of the identified proteins}

The increased and decreased intensities of the selected spots were ascertained chronologically by comparison of
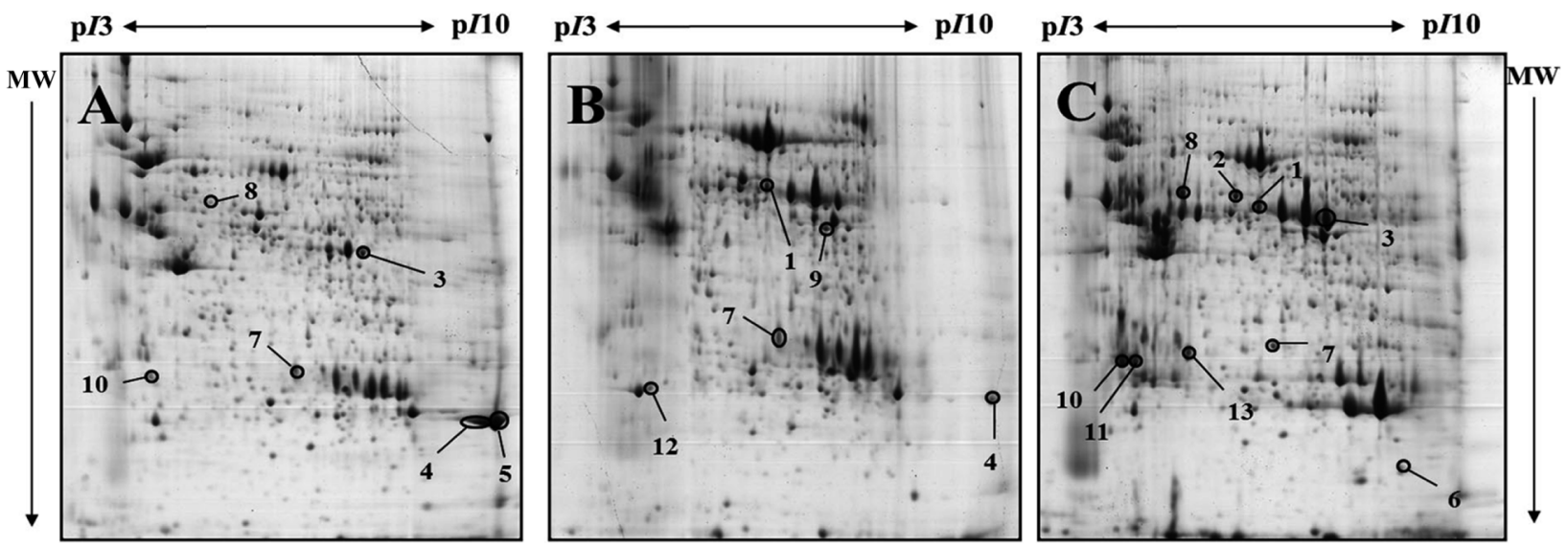

Figure 1. Representative 2-DE gels of pancreas of 4-day-old, 19-day-old and 14-month-old miniature pigs by developmental stages, visualized by Commassie blue staining. Samples of $1 \mathrm{mg}$ protein were separated on pH3-10 non-linear IPG strip (24cm) following by $8-18 \%$ gradient SDS-PAGE in the second dimension. Proteins were detected by Coomassie brilliant blue G-250 and compared using ImageMaster ${ }^{\mathrm{TM}}$ 2D Platinum Software version 5.0. A: 2-DE gel of 4-day old miniature pig(neonate), B: 2-DE gel of 19-day old miniature pig, C: 2-DE gel of 14-month old miniature pig. The closed circles indicate 13 differentially expressed protein spots in the 4-day-old miniature neonate pig, 19-day-old miniature piglet and 14-month-old miniature adult pig. 


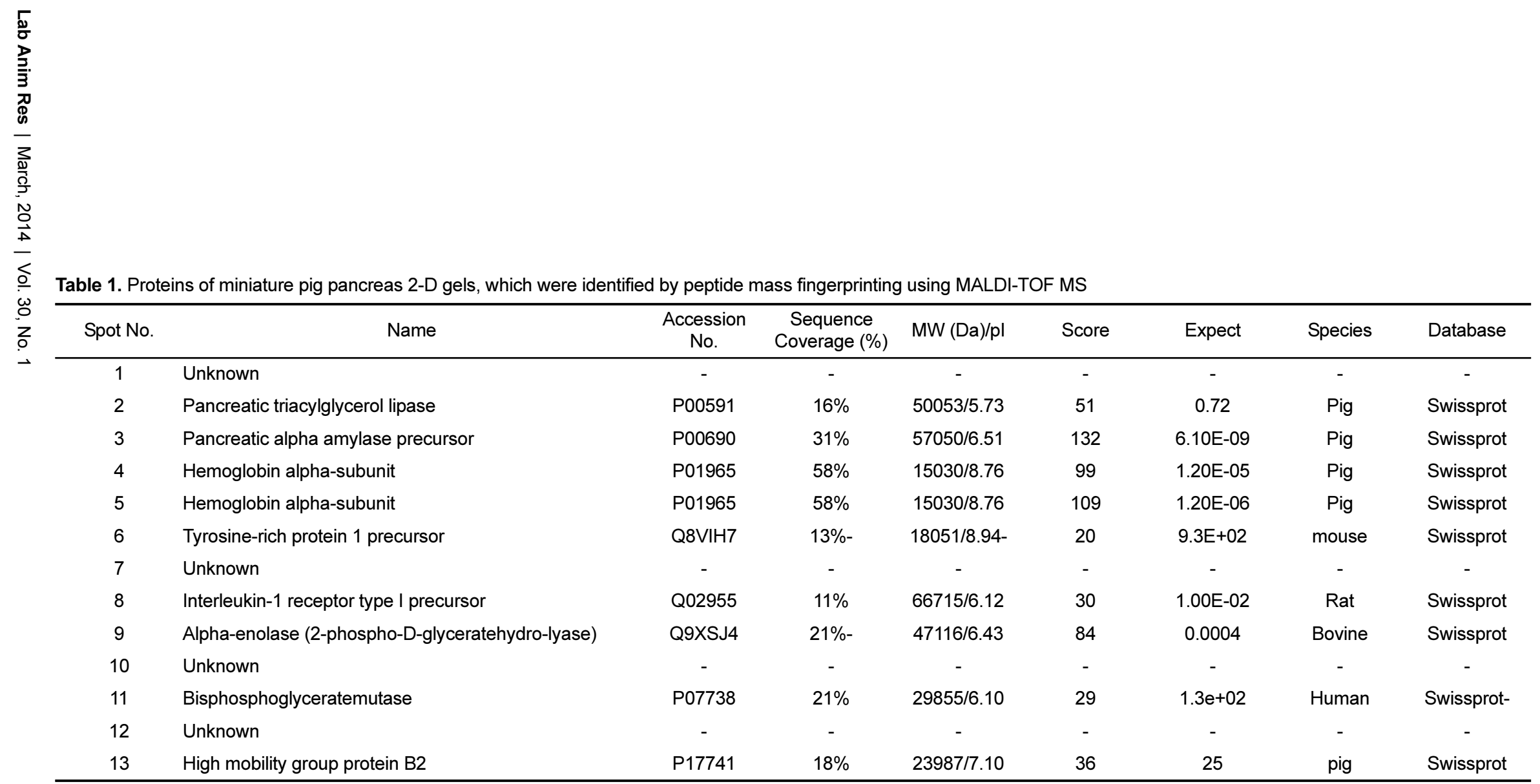

Table 1. Proteins of miniature pig pancreas 2-D gels, which were identified by peptide mass fingerprinting using MALDI-TOF MS 


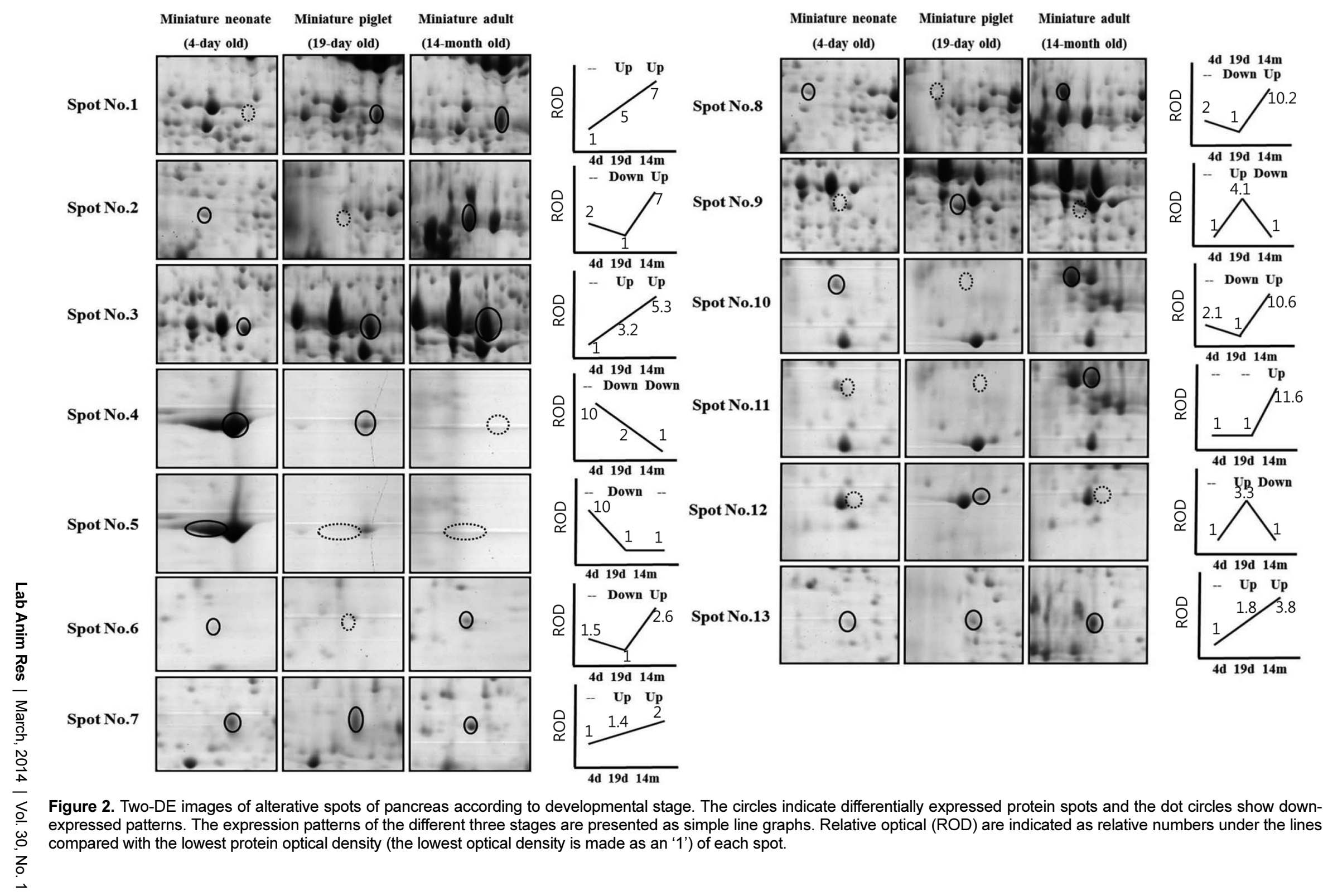


the miniature pigs from the neonate stage to adulthood (Figure 2). The expression of pancreatic triacylglycerol lipase (spot 2), tyrosine-rich protein 1 precursor (spot 6) and interleukin-1 receptor type Iprecursor (spot 8) were down- and up-regulated. Although spot 10 displayed a similar intensity, correct identification was not achieved. Pancreatic alpha amylase precursor (spot 3) and high mobility group protein B2 (spot 13) were both upregulated. Spots 1 and 7 displayed similar intensity patterns, but correct identification was again not achieved. Hemoglobin alpha-subunit spots (spots 4 and 5) were shown side-by-side; the spot intensities were variable, being either both down-regulated or down-regulated and unchanged, respectively. Bisphosphoglyceratemutase (2, 3-bisphosphoglycrerate mutase; spot 11) expression was either unchanged or up-regulated. The expression of alpha-enolase (2-phospho-D-glyceratehydro-lyase; spot 9 ) and spot no. 12 was up-regulated and down-regulated, respectively. Spot 12, which showed similar spot intensity, was not identified correctly.

\section{Discussion}

This study is, to our knowledge, the first report of protein expression of pancreas in miniature pigs according to the developmental stage. Although xenotransplantation of pancreas using pathogen-free miniature pigs has been explored for a few decades, few studies have examined the proteome of the whole pancreas of miniature pigs at the chronological developmental stages (in this study, neonate, 19-day old and 14-month old miniature pigs). A comprehensive understanding of protein expressional alteration in the pancreas can provide useful biological and clinical information. About 300 proteins with isoelectric points of 3-10 and molecular weight of 10-100 $\mathrm{kDa}$ were detected. Of 289 spots, 13 were significantly changed during development; of these, nine spots were functionally identified. Of these identified proteins, few were directly related with pancreas functions. For instance, pancreatic triacylglycerol lipase is required for efficient dietary triglyceride digestion [18,19]. Although this enzyme may play a role in fat metabolism, its expression varies developmentally and by tissue [19]. Pancreatic alpha amylase precursor is found in the pancreas and salivary gland [20]. Alpha-amylase is a typical secretory protein that is subject to glycosylation machinery during its biosynthesis [21,22]. The glycosylation is preceded by proteolytic processing during the biosynthesis of the alpha-amylase molecule [23]. The mammalian interleukin-1 receptor type 1-Toll-like receptor superfamily has important roles in innate immunity, inflammatory responses, stress response and fatal immune disorders [24-27], and it undergoes intramembrane proteolytic processing [28]. Several studies have reported the relationship of interleukin-1 receptor type 1 with pancreatitis [29-31]. In addition, inflammation in type 2 diabetes has been linked to interleukin-1 receptor type 1 [30]. Alpha-enolase is a $48-\mathrm{kDa}$ protein that is crucial in the glycolytic pathway [32], where it catalyzes the formation of phosphoenolpyruvate from 2-phosphoglycerate, the second of the two high energy intermediates that generate ATP in glycolysis [33].

Despite the numerous studies of xenotransplantation between pigs and humans for considerable times, the proteomic alterations of various organs during development, whether or not these changes are critical in the particular developmental stage, has not been considered. Additionally, data concerning the proteome of porcine pancreatic tissue are scant [5], with no attempt to investigate the transplantation-relevant proteomic expressional relationships and differences between human and miniature pigs.

Knowledge of the alteration of the protein complement would provide valuable information to overcome the problems posed by the immunologic barrier, microbiologic differences and xenospecies, which presently hinder xenotransplantation. From the present data, the pancreactic proteomic alterations in the developmental stages appear to contain several enzymatic activities and immune responses, and have hematological relevance. Although the scope of the data was hindered by technical problems, the data provides the first reference of the protein expression during pancreas development, which will be useful in further proteome analyses of the porcine pancreas with respect to xenotransplantation.

\section{Acknowledgments}

This work was supported by the grants from the BioIndustry Technology Development Program Ministry of Agriculture, Food and Rural Affairs, Korea to Prof. Je Kyung Seong (311054-03-2HD110), and this work was also supported by Soonchunhyang University Research Fund to Prof. Sun Shin Yi. 


\section{References}

1. Cooper DK, Gollackner B, Sachs DH. Will the pig solve the transplantation backlog? Annu Rev Med 2002; 53: 133-147.

2. Platt JL. Physiologic barriers to xenotransplantation. Transplant Proc 2000; 32(7): 1547-1548.

3. Ryu JM, Kim DH, Lee MY, Lee SH, Park JH, Yun SP, Jang MW, Kim SH, Rho GJ, Han HJ. Imaging evaluation of the liver using multi-detector row computed tomography in micropigs as potential living liver donors. J Vet Sci 2009; 10(2): 93-98.

4. Ibrahim Z, Busch J, Awwad M, Wagner R, Wells K, Cooper DK. Selected physiologic compatibilities and incompatibilities between human and porcine organ systems. Xenotransplantation 2006; 13(6), 488-499.

5. Tucker A, Belcher C, Moloo B, Bell J, Mazzulli T, Humar A, Hughes A, McArdle P, Talbot A. The production of transgenic pigs for potential use in clinical xenotransplantation: baseline clinical pathology and organ size studies. Xenotransplantation 2002; 9(3): 203-208.

6. Ando A, Ota M, Sada M, Katsuyama Y, Goto R, Shigenari A, Kawata H, Anzai T, Iwanaga T, Miyoshi Y, Fujimura N, Inoko H. Rapid assignment of the swine major histocompatibility complex (SLA) class I and II genotypes in Clawn miniature swine using PCR-SSP and PCR-RFLP methods. Xenotransplantation 2005; 12(2): 121-126.

7. Park CG, Kim JS, Shin JS, Kim YH, Kim SJ. Current Status and Future Perspectives of xenotransplantation. J Korean SocTranplant 2009; 23(3): 203-213.

8. Vodicka P, Smetana K Jr, Dvoránková B, Emerick T, Xu YZ, Ourednik J, Ourednik V, Motlík J. The miniature pig as an animal model in biomedical research. Ann N Y Acad Sci 2005; 1049: 161-171.

9. Choi JS, Cho YK, Y oon SH, Kwon SO, Koo DB, Yu K. Proteomic analysis of porcine pancreas development. BMB Rep 2009; 42(10): 661-666.

10. Han HJ, Kang SS, Park SH. Tissue specific expression of lipid metabolism related molecules in digestive organs of miniature pigs. Lab Anim Res 2010; 26(3): 273-278.

11. Lee MS, Song KD, Yang HJ, Solis CD, Kim SH, Lee WK. Development of a type II diabetic mellitus animal model using Micropig $^{\circledR}$. Lab Anim Res 2012; 28(3): 205-208.

12. Cozzi E, Bosio E. Islet xenotransplantation: current status of preclinical studies in the pig-to-nonhuman primate model. Curr Opin Organ Transplant 2008; 13(2): 155-158.

13. Marigliano M, Bertera S, Grupillo M, Trucco M, Bottino R. Pigto-nonhuman primates pancreatic islet xenotransplantation: an overview. Curr Diab Rep 2011; 11(5): 402-412.

14. Rood PP, Buhler LH, Bottino R, Trucco M, Cooper DK. Pig-tononhuman primate islet xenotransplantation: a review of current problems. Cell Transplant 2006; 15(2): 89-104.

15. Steiner S, Anderson NL. Pharmaceutical proteomics. Ann N Y Acad Sci 2000; 919: 48-51.

16. Görg A, Obermaier C, Boguth G, Harder A, Scheibe B, Wildgruber R, Weiss W. The current state of two-dimensional electrophoresis with immobilized $\mathrm{pH}$ gradients. Electrophoresis 2000; 21(6): 1037-1053.

17. Shevchenko A, Wilm M, Vorm O, Mann M. Mass spectrometric sequencing of proteins silver-stained polyacrylamide gels. Anal Chem 1996; 68(5): 850-858.

18. Lewe ME. The triglyceride lipases of the pancreas. J Lipid Res 2002; 43(12): 2007-2016.

19. Mahan JT, Heda GD, Rao RH, Mansbach CM 2nd. The intestine expresses pancreatic triacylglycerol lipase: regulation by dietary lipid. Am J Physiol Gastrointest Liver Physiol 2001; 280(6): G1187-1196.

20. Hagenbüchle O, Bovey R, Young RA. Tissue-specific expression of mouse-alpha-amylase genes: nucleotide sequence of isoenzyme mRNAs from pancreas and salivary gland. Cell 1980; 21(1): 179187.

21. Doyon Y, Home W, Daull P, LeBel D. Effect of C-domain Nglycosylation and deletion on rat pancreatic alpha-amylase secretion and activity. Biochem J 2002; 362(Pt 1): 259-264.

22. Miyata S, Akazawa T. Biosynthesis of rice seed alpha-amylase: proteolytic processing and glycosylation of precursor polypeptides by microsomes. J Cell Biol 1983; 96(3): 802-806.

23. Miyata S, Akazawa T. alpha-Amylase biosynthesis: evidence for temporal sequence of $\mathrm{NH} 2$-terminal peptide cleavage and protein glycosylation. Proc Natl Acad Sci USA 1982; 79(21): 6566-6568.

24. Akira S, Takeda K. Toll-like receptor signalling. Nat Rev Immunol 2004; 4(7): 499-511.

25. Creagh EM, O’Neill LA. TLRs, NLRs and RLRs: a trinity of pathogen sensors that co-operate in innate immunity. Trends Immunol 2006; 27(8): 352-357.

26. Subramaniam S, Stansberg C, Cunningham C. The interleukin 1 receptor family. Dev Comp Immunol 2004; 28(5): 415-428.

27. Takeda K, Akira S. Toll-like receptors in innate immunity. Int Immunol 2005; 17(1), 1-14.

28. Elzinga BM, Twomey C, Powell JC, Harte F, McCarthy JV. Interleukin-1 receptor type 1 is a substrate for gamma-secretasedependent regulated intramembrane proteolysis. J Biol Chem 2009; 284(3): 1394-1409.

29. Abcouwer SF, Norman J, Fink G, Carter G, Lustig RJ, Souba WW. Tissue-specific regulation of glutamine synthetase gene expression in acute pancreatitis is confirmed by using interleukin-1 receptor knockout mice. Surgery 1996; 120(2): 255-263.

30. Chentouf M, Dubois G, Jahannaut C, Castex F, Lajoix AD, Gross R, Peraldi-Roux S. Excessive food intake, obesity and inflammation process in Zucker fa/fa rat pancreatic islets. PLoS One 2011; 6(8): e22954.

31. Fink GW, Norman JG. Specific changes in the pancreatic expression of the interleukin 1 family of genes during experimental acute pancreatitis. Cytokine 1997; 9(12): 10231027.

32. Subramanian A, Miller DM. Structural analysis of alpha-enolase. Mapping the functional domains involved in down-regulation of the c-myc protooncogene. J Biol Chem 2000; 275(8): 5958-5965.

33. Wold, F. (1971) The Enzymes; (Boyer, P.D., ed) $3^{\text {rd }}$ Ed. 5, pp. 499508, Academic Press, New York, USA. 